\title{
The Impact of Online vs. Offline Acculturation on Purchase Intentions: A Multigroup Analysis of the Role of Education
}

\author{
Hatice Kizgin** \\ University of Bradford, Faculty of Business, Law and Social Sciences \\ Richmond Road, Bradford BD7 1DP \\ Phone: +44 (0)1274 232653 \\ Email: h.kizgin@bradford.ac.uk \\ Ahmad Jamal \\ Cardiff University, Cardiff Business School \\ R36, Aberconway Building, Colum Road, Cathays, Cardiff, CF10 3EU \\ Phone: +44 (0)292087 6838 \\ Email: jamala@ cardiff.ac.uk \\ Yogesh K. Dwivedi \\ Emerging Markets Research Centre (EMaRC), School of Management \\ Swansea University Bay Campus, Swansea, UK \\ Phone: +44 (0)1792 602340 \\ Email: y.k.dwivedi@swansea.ac.uk \\ Nripendra P. Rana \\ University of Bradford, Faculty of Business, Law and Social Sciences, UK \\ Richmond Road, Bradford BD7 1DP \\ Phone: +44 (0)1274 232633 \\ Email: n.p.rana@bradford.ac.uk
}

\begin{abstract}
The aim of this research is to determine the extent of online and offline acculturation preferences affecting purchase intentions within a minority ethnic community. This study investigates the role of social media as an agent in terms of how it influences acculturation and consumption. It also investigates the moderating role of education level. The findings highlight the significance of investigating language and friendship orientations and subsequent acculturation preferences. Empirical results confirm the impact of language and friendship orientations on enculturation/acculturation, which in turn impact purchase intentions. The results suggest differences among three groups in terms of their education level. The study discusses contribution to theory and provides future research directions, while offering useful practical implications for marketers.
\end{abstract}

Keywords: Online Acculturation, Offline Enculturation/Acculturation, Purchase Intentions, Education, Multigroup Analysis 


\section{Introduction}

Consumer acculturation involves processes related to the learning of a new culture (Jamal et al., 2015). Prior research has investigated antecedents, processes and outcomes of consumer acculturation among ethnic minority consumers in an offline context (Askegaard, Arnould and Kjeldgaard, 2005; Kizgin et al., 2018a; Peñaloza, 1994). Such studies report preference for language use (inside and outside home) and social interactions (in the form of friendship orientations) as key drivers aligned with acculturation outcomes. Acculturation agents defined as "individuals or institutions who serve as sources of consumer information and/or models of consumption behavior" (Peñaloza, 1989, p.116) play an important role in determining the outcomes of consumer acculturation (Askegaard et al., 2005; Kizgin et al., 2018a; Peñaloza, 1994).

However, there has been a significant growth in the use of social media by ethnic minority consumers over the recent years. Scholars like Dey, Yen and Samuel (2020) argue that the convenience and connectedness provided by new media platforms promote assimilation, integration or acculturation beyond the users' own community. This is because ethnic minority consumers can connect, socialize and widen their friendship networks via social networking sites facilitating strengthening of ties not only with in-group but also with out-group members. This allows them to break away from stereotypes (e.g., isolation and segregation) that are commonly associated with ethnic communities. This also helps facilitate their integration into the broader host culture and society.

Ethnic minority consumers also face a choice of using either their own ethnic language or majority language when using social networking sites. Together with their friendship preferences on social media, this choice can highlight and uphold the fact they are different from the majority or their desire and motivation to integrate certain elements of the mainstream culture. Such a choice can have important consequences for them in terms of their 
psychological well-being and consumer acculturation. For example, Li and Tsai (2015) report that using social media in the English language helps Hispanics to develop strong orientation toward the American culture, while the use of social media in the Spanish language reinforces enculturation (i.e. heritage culture). Similarly, Kizgin et al. (2018b) show that preference of the host culture language has a positive effect on acculturation and a negative effect on enculturation.

While a recent work points to the complexity of acculturation given the significant rise in the use of digital technologies (Dey et al., 2020), research seldom considers the fact that ethnic minority consumers' acculturation experiences are shaped by interactions both in offline and online contexts. Accordingly, it is possible that ethnic minority consumers' choices on new media in the form of friendship and language preferences may impact acculturation strategies in the physical domain, which in turn, impact their specific purchase intentions. Support comes from Kizgin et al. (2018b) who report that ethnic minority consumers engage with online networks and take part in heritage consumer cultures. Research also testifies that cultural orientations influence consumers' purchase intentions, which are affected by the information they use through online social networks (Wang, Yu and Wei, 2012).

The degree to which an ethnic minority consumer acculturates to the host culture influenced by language and education may be a more important predictor of consumer behavior than country of birth (Ogden et al., 2004). Scholars recognize that little is known about how the specific role of online acculturation predicts acculturation preferences and subsequent consumption choices (e.g. Kizgin et al., 2020). We address this research gap by simultaneously investigating the effects of online and offline acculturation on ethnic minority consumers' purchase intentions. Despite the emergence of digital technologies, the role of online acculturation preferences shaping offline acculturation preferences and how this informs consumer behavior is limited (Kizgin et al., 2018b; Kizgin et al., 2020). Social media networks 
may play an integral role in the lives of ethnic minority consumers and facilitate interactions with others with significant implications for consumer acculturation. Social media has become an aspect of day-to-day life, while it is worthwhile to examine the "interlocking networks of cultural consuming communities in market systems" (Kizgin et al., 2020, p.6). This research gap is addressed by investigating variations in online acculturation, acculturation/enculturation preferences and purchase intentions.

Moreover, characteristics of education influence the process of acculturation preferences (e.g. Makarova \& Birman, 2016) and, therefore, education is seen as an important determinant of acculturation process (Berry et al., 2011). In terms of consumption choices, it is possible for better educated ethnic minority consumers to engage in information search behavior differently than lower educated ones. They may also rely less on the opinion of others when it comes to making specific consumption choices. This is because such individuals may become better informed and knowledgeable about existing product alternatives and, hence, can discriminate between relevant and irrelevant information more effectively and independently (Alba \& Hutchinson, 1987, 2000; Johnson \& Russo, 1984). However, little is known about the moderating effects of education level on the way online acculturation captured via friendship orientation and language use can impact off line acculturation. Moreover, we do not know if the relationship between acculturation and purchase intentions becomes stronger or weaker due to varying levels of education.

Accordingly, this research formulates two research questions: Firstly, to what extent ethnic minority consumers' online acculturation preferences shape offline acculturation and how this in turn influences their purchase intentions? Second, what role ethnic minority consumer's education level plays in explaining cultural orientations and consumption choices made by ethnic minority consumers. 
In order to address the research questions, this study aims to investigate the link between ethnic minority consumers' online acculturation (friendship orientation and language use) on offline acculturation and between offline acculturation and purchase intentions. Also, the research aims to investigate the moderating effects of an ethnic minority consumer's education level in explaining online and offline acculturation and purchase intentions. A multigroup analysis method is employed to relate the differences within various education level groups. By doing so, the aim of this research is to help scholars and practitioners in understanding the role of online acculturation for ethnic consumer behavior and marketing. Immigrant populations in Western countries have significantly increased (Eurostat, 2019; Jamal, 2003) undergoing a process of change that may relate to their heritage and host cultures in different degrees (Berry et al., 2011; Laroche \& Jamal, 2015). Accordingly, the existence of a multicultural marketplace is characterized by ethnic, racial, religious and national differences (Peñaloza and Gilly, 1999) and represent important challenges and opportunities to marketers.

This paper is organized into the seven sections. The next Section 2 includes literature related to language, friendship orientation, preferences of enculturation/acculturation and the role of education. Section 3 presents conceptual model and formulates various hypotheses. This is followed by methodology (i.e. Section 4) and the findings (i.e. Section 5). The theoretical and practical implications are then discussed in Section 6. Finally, Section 7 concludes with limitations and suggestions for future research.

\section{Literature Review}

Ethnic consumer behavior is influenced by enculturation and acculturation preferences. Enculturation is the process of learning the heritage culture (Kizgin et al., 2018a; Schwartz et al., 2010), whereas acculturation refers to learning of a new culture based on contact and interactions with culturally dissimilar people (Laroche \& Jamal, 2015). 
Kaplan and Haenlein (2010, p.61) define social media as "a group of Internet-based applications that build on the ideological and technological foundations of Web 2.0 and that allow the creation and exchange of user generated content". Social media offers opportunities to communicate with others and develop and nurture social relationship as well as share views and provide suggestions (e.g., Alalwan et al., 2016; Dwivedi et al., 2015; Ellison et al., 2007; Ellison \& Boyd, 2013; Kapoor et al., 2018). Hence, socializing and nurturing relationships on social media with the host or home culture members is a resource and a form of building friendship networks and forming social capital (Lin et al., 2001; Shen et al., 2016).

Social networking sites enable ethnic minority consumers to connect and form relationships with everyone including people from ethnic cultural background, of the host society and people around the globe. In such a context, we do not know if an ethnic minority consumer's tendency to network and form relationships with in-group and out-group members online can impact specific acculturation orientations in offline contexts. For example, such a consumer may have a tendency to mainly socialize and form relationships on social networking sites with people of their own cultural background. In doing so, they may use online social networks as a resource and a form of social capital linked with their own culture of origin. Support comes from scholars who argue that online social networks provide interpersonal communication mechanism to maintain social relationships within ethnic minority groups (Dwivedi et al., 2015; Yu, Foroudi \& Gupta, 2019). Thus, ethnic minority consumers may use social media as a mechanism to strengthen their social and cultural relationships through communication with people of their own cultural background, that help form consumer learning processes. This can potentially impact their cultural tendencies and consumption choices in an offline context. On the other hand, a person may largely prefer socializing and forming relationships on social networking sites with people of other cultures. This can also impact their cultural tendencies and consumption choices in an offline context. Support comes 
from Lindridge, Henderson and Ekpo (2015), who state that social media provides a platform for consumers to develop and reinforce their beliefs and values that resonate online i.e. the pursuit to maintain or resist their heritage culture and host culture and progressively to the same extent in an offline context. Therefore, social media is an agent that facilitates ethnic minority consumers' identity (Foroudi, Marvi \& Kizgin, 2020; Jafari \& Visconti, 2015) in both online and offline contexts.

\subsection{Acculturation-Friendship}

The role of social interactions is a key consideration when examining acculturation preferences. Ethnic minority consumers who are in frequent interaction with the host culture members are influenced by the host culture (Kizgin et al., 2018a). Friendships influence consumption behavior (Xu et al., 2004) through engagement and connection with the social relationships (Laroche et al., 2009). Social media allows individuals to connect with their network, maintain existing networks and build new relationships (Acquisti \& Gross, 2006; Ellison, Steinfield, \& Lampe, 2007). According to Eurostat (2019), 56\% of individuals in the age group 16-74 years have participated in social networking sites in the EU, while among younger people between 16 and 24 years the participation rate is $88 \%$. The various networks (i.e. social media) give opportunity to provide strengths and weaknesses to the consumer cultural process. Given this, ethnic minority consumers may demonstrate a strength of relationships of the ethnic or host friendships with a propensity of respective consumption patterns.

Research argues that the primary role of adaptation to the host culture is determined through social interactions with the host culture individuals (Arends-Tóth \& van de Vijver, 2006). An individual who values acculturation i.e. dominance of social interactions with the host culture will exhibit changes in behaviors related to the host culture. Social networks and social interactions represent "dual sets of acculturation agents" (Peñaloza, 1994, p.49) and 
provide consumers with culture-specific influences on their behavior (Keefe \& Padilla, 1987; $\mathrm{Xu}$ et al., 2004). Relevant literature argues that social support is the primary motivation to use social networking sites (Kim et al., 2011). Differences in the motivational factors between culturally distinct user groups can also exist. Jackson and Wang (2013), for example, have shown that Chinese users nurture their friendships, while young American users primarily seek to obtain information.

\subsection{Acculturation-Language use}

Ethnic minority consumers are largely bilingual (Kizgin et al., 2019) and, hence, have a choice of communicating in their native or host country language when using social media. A powerful predictor of effective social media engagement is language use (Kizgin et al., 2018b; Hilte et al., 2016). Research has highlighted that the frequent use of the heritage language is an indicator to maintain the home culture (Arends-Tóth \& van de Vijver, 2008; Kizgin et al., 2018b; Yagmur \& Van de Vijver, 2012). With growing generations of immigrants (e.g. Turkish-Dutch in the Netherlands, British-Indians in the UK), there is a trend that later generations are more fluent in speaking the host country language. This is stimulated and advanced through exposure in school, friends/peers as well as media (e.g. Hui et al., 1992) and, therefore, is related to speaking and engaging with friends. For example, Ueltschy (1997) finds that the preferred language in advertisements is Spanish for low acculturated individuals in the US, while English language is preferred by more acculturated individuals. Research also shows that ethnic minority consumers who engage socially with and use the host language are influenced by the host culture as a result of cultural learning process (Kizgin et al., 2018a). Language preferences (i.e. home or host) allows experiencing of respective cultural identities, while individuals are on social media. 


\section{Research Model and Hypotheses Development}

Our conceptual framework is based on a review of the literature on consumer acculturation and enculturation (Askegaard et al., 2005; Bercerra \& Korgaonkar, 2010; Jamal et al., 2015; Kizgin et al., 2018a; Peñaloza, 1994), digital acculturation (Dey et al., 2020; Kizgin et al., 2020), social media use (Kaplan \& Haenlein, 2010; Kizgin et al., 2020; Dwivedi et al., 2015), friendship orientations (Lin et al., 2001; Shen et al., 2016), language use (Li \& Tsai, 2015), consumer behavior (Wang, Yu, \& Wei 2012; Xu et al., 2004) and the role of education (Berry et al., 2011; Makarova \& Birman, 2016; Ogden et al., 2004).

Past studies (e.g. Jamal et al., 2015; Kizgin et al., 2018a) report that consumers' purchase intentions are influenced by their acculturation and enculturation orientations. Likewise, language preference is found as an important indicator of consumer acculturation outcomes. It plays an important role when a consumer engages with other individuals using either their native or mainstream language on social media. Hassler et al. (2019) extends the existing body of research to establish how cross group friendship can affect majority members' acculturation preferences. However, all these relationships are not studied together. Moreover, consumer's education level may potentially play a significant role in explaining the impact of language use and friendship orientation onto acculturation preferences and between acculturation preferences and purchase intentions. For example, relationships of language use and friendship orientations may have a different impact on acculturation preferences for individuals with lower and higher education levels. Similarly, the role of education between acculturation/enculturation and purchase intention can be decisive and has not been explored.

\subsection{Proposed Research Model}

The proposed research examines the extent to which online acculturation (i.e. friendship orientation and language use) impacts acculturation/enculturation preferences and purchase intentions. The conceptual model presented in Figure 1 postulates that online 
acculturation is positively related to acculturation and negatively related to enculturation. In line with previous research (Kizgin et al., 2018b) acculturation/enculturation preferences impact purchase intentions. Education is conceptualized as a moderator. The proposed relationships and associated hypotheses are discussed in detail in the next section.

[Insert Figure 1 here]

\subsection{Hypotheses Development}

Communication with friends on social networking sites has an impact on the decision making of consumers and, therefore, has led to the interaction of products and services (Brown et al., 2007). Moreover, friendship communication is argued as the strongest predictor of behaviors towards products (Lueg \& Finney, 2007). Research by Ellison et al. (2007) shows that social networking sites influence the upholding of offline relationships. Research argues that ethnic minorities reinforce their identification in online context through frequent interaction on social media (Lindridge, Henderson, \& Ekpo 2015).

Language has been found to impact acculturation preferences (Kizgin et al., 2018b; Li \& Tsai, 2015). In a social media context, individuals may prefer to use their own language or the mainstream language depending on the requirements of the recipients while engaging with them in the social media (Kizgin et al., 2018b). The prior literature has also highlighted the need and importance of language preference in the context of ethnic marketing as far as winning the trust of consumers is linked with it (Jamal et al., 2015). Support comes from information seeking behavior (Park \& Cho, 2012), language use (Kizgin et al., 2018b) and individual identification (Brown et al., 2007). For example, Hsu et al. (2011) affirm that friends on social networking sites have a significant impact on socialization. Furthermore, research has indicated that consumer purchase intentions are influenced by socialization on social networks (Wang et al., 2012). As such, social networks can be created further in terms of online acculturation through social interactions and close relationships pursed using online media 
(Chang \& Chuang, 2011). Further research by Kizgin et al. (2018b) suggests that the online host language use affects socialization with host culture friends in offline context. Based on the discussion above, the first set of hypotheses is proposed as:

H1a. Friendship orientation has a negative effect on enculturation.

H1b. Friendship orientation has a positive effect on acculturation.

H2a. Language use has a negative effect on enculturation.

H2b. Language use has a positive effect on acculturation.

Some other studies report the effects of ethnicity on purchase intentions (e.g., Laroche et al., 1997; Burton, 2002; Luedicke, 2011). A recent work has also reported an evidence of relationship between acculturation/enculturation with purchase intentions (e.g., Kizgin et al 2018b). It is argued that the information individuals use is impacted by their cultural orientation (Kizgin et al., 2020; Wang et al., 2012). An ethnic minority consumer's identification i.e. acculturation/enculturation plays a role in how information is processed and how marketingrelated decision can be influenced. Thus, ethnic minorities who have adapted to the mainstream culture manifest to consumption that is comparable to the host community (Askegaard \& Arnould, 2005). Therefore, the following hypothesis is proposed:

H3a. Enculturation has a positive impact on purchase intentions.

H3b. Acculturation has a positive impact on purchase intentions.

Demographic antecedents e.g. age, education, income, occupation have been identified to influence consumer acculturation outcomes (Kairullah \& Kairullah, 1999; Maldonado \& Tansuhaj, 2002; Peñaloza, 1989). However, to date, the role of online acculturation moderated by education is not investigated in explaining acculturation orientations among ethnic minority consumers. Education levels are important as consumers learn skills and culturally appropriate behaviors through interactions with friends, institutions like schools and media (Peñaloza, 1994; Yagmur \& van de Vijver, 2012). 
Early research by Padilla (1980) also establishes that educational level is positively associated with acculturation, while lower education level is associated with less acculturated individuals. Therefore, it can be argued that the adaptation to the host culture (i.e. acculturation) is an outcome of a higher level of education. This association stems from the disposition as a result of consumer learning processes (Despande et al., 1986; Askegaard \& Arnould, 2005). The socio-cultural adaptation is also found to result from education and occupation success (Quarasse \& van de Vijver, 2004) with a positive influence on psychological adaptation (Van de Vijver \& Phalet, 2004). Education level is shown to impact stronger mainstream/host attitudes and behaviors while the effects on heritage attitudes and behavior are weaker with increasing education level (Gupta, 2012; Yagmur \& van de Vijver, 2012).

Therefore, individuals with a higher education accompanied by higher income, may acculturate more compared to people with a lower education and lower income levels. Accordingly, research should consider the moderating role of education level in acculturation research to capture individual differences beyond the comparison of low or high acculturation classification. Based on the study by Maldonado and Tansuhaj (2002), a lower education level is found for individuals in the separation category, whereas acculturated individuals are identified with higher education categories. Support comes from Yaprak (2008) in examining foreign brands that education levels along age and income levels have a significant impact on consumer acculturation. Moreover, Gupta (2012) finds that a high-level educational qualification has a significant impact on consumer acculturation. Their study involving Indian consumers reveals that higher education is associated with 'Western spirit and content' and encourages assimilation and influences higher levels of consumer acculturation. These findings are in line with Yaprak (2008) who argues that a higher education level asserts host culture preferences. In addition, higher education levels are associated with host language preferences in contrast to lower education levels indicate the embedment in social networks (Leung et al., 
2005), while less acculturated ethnic minority consumers are more likely to be consumers of heritage language media. The above discussion and findings support the hypothesis to predict a positive association between higher education level and host acculturation. Hence, the hypothesis is proposed as followed:

H4. Education level moderates the relationships between a) friendship orientation and enculturation, b) friendship orientation and acculturation, c) language use and enculturation, d) language use and acculturation, e) enculturation and purchase intentions and f) acculturation and purchase intentions such that the relationships are stronger when ethnic minority consumer's education level is higher versus lower.

\section{Methodology}

\subsection{Sample and data collection}

The sample utilized in this study is selected from the Netherlands and focused on the TurkishDutch community. The study uses a self-administered questionnaire to collect data from over 500 respondents. Forty-six percent of the respondents were female, and the remaining fiftyfour percent were male. Education level of respondents is divided into three existing groups defined by the highest degree or level of education. Respondents in Group 1 (14.6\%) have indicated their highest education defined by secondary education. Group 2 was $39.1 \%$ with a higher education completion, while Group 3 is formed by a doctorate or $\mathrm{PhD}$ degree with $46.3 \%$ of respondents.

\subsection{Measures}

The measurement of language preferences on social media is based on Kaplan and Haenlein's (2010) framework and Mendoza's (1989) Cultural Lifestyle Inventory (CLSI) applied to the social media context. The measurement of friendship orientation is adapted from Xu et al. (2004). Consumer acculturation and enculturation are based on Arends-Tóth and van de Vijver's (2007) "two-statement method," method including 10 items in which first one 
assesses the respondent's cultural orientation in relation to the host culture (e.g., "I spend most of my social time with Dutch people") and then assesses the respondent's behavior as it relates to his or her own ethnic heritage (e.g., "I spend most of my social time with Turkish people"). Purchase intention items are adopted from Coyle and Thorson (2001). Each item was scored on a 7-point Likert scale ranging from "strongly disagree" to "strongly agree".

\section{Data Analysis and Findings}

This study used Confirmatory Factor Analysis (CFA), Multi-Group Analysis, and Structural Equation Modelling (SEM) to test the hypotheses.

\subsection{Single-group confirmatory factor analysis}

The measurement model for the total sample irrespective of level of education indicates a good overall fit. Parsimony fit $\chi^{2} / \mathrm{df}=2.283$, adjusted goodness of fit index $($ AGFI) $=0.861$ comparative fit index $(\mathrm{CFI})=0.944$; incremental fit index $(\mathrm{IFI})=0.944$; root mean square error of approximation $(\mathrm{RMSEA})=0.029$.

\subsection{Single-group structural equation analysis}

The next step after the measurement model validation is the structural equation analysis using AMOS 22.0 for assessing the relationships among the latent variables (Figure 2 and Table 3). This analysis confirms that the proposed factor structure is an appropriate representation of the underlying data. The goodness of fit statistics shows a good fit, given the large sample size of $>500$ (Hair et al., 2010); parsimony fit $\mathrm{x}^{2} / \mathrm{df}=2.450, \mathrm{CFI}=0.936 \mathrm{AGFI}=$ 0.854 and $\mathrm{RMSEA}=0.05$.

\subsection{Multi-group analysis}

The study follows multi-group analysis guidelines (Byrne, 2009). We constructed the following three groups based on respondents' education level: (1) respondents who were Group $1(n=75)$ had education level of secondary education; (2) Education Group $2(n=201)$ with 
higher education completion; and (3) respondents with Education Group 3 formed by a doctorate or $\mathrm{PhD}(\mathrm{n}=238)$.

A multi-group analysis is conducted to examine parameter estimate differences between the groups. The equivalence test is to validate the factorial structure of the measurement model for each group separately before invariance across the groups is tested (Byrne, 2009).

Convergent validity is achieved with high factor loadings above the recommended threshold of 0.5 (Kline, 2011). The average variance extracted estimates (AVE) are between 0.535 and 0.698 and composite reliability score for each construct is between 0.883 and 0.953 . These results suggest acceptable evidence of measurement model validity (Fornell and Larcker, 1981). Table 1 presents the factor loadings, Cronbach's alpha values, AVE and composite reliability (CR) measures, with the mean scores and effect sizes shown in Table 2. To test if education is a boundary condition the equivalence of means related to each factor is tested.

[Insert Table 1 here]

[Insert Table 2 here]

\subsection{Multi-group Structural Equation Analysis}

To accept the configural invariance of the hypothesized multi-group model, an unconstrained multi-group measurement model is examined next (Hu \& Bentler, 1999). Invariance decisions should however not be based on Chi-square values because of sensitivity to sample size (Byrne \& van de Vijver, 2010; Cheung \& Rensvold, 2002). Invariance is accepted with differences in CFI values and are set as equal to 0.01 and -0.01 (Cheung and Rensvold, 2002). The configural invariance model (baseline Model 1 across groups) indicates a satisfactory fit, given the large sample size of 514 (Hair et al., 2010) $\left(\chi^{2} / \mathrm{df}=1.749, \mathrm{CFI}=\right.$ 0.904, RMSEA $=0.038$, which indicated that the model fits all groups well and therefore the factor structure is identical across the three groups. 
The next step is to assess metric invariance by increasing constraints to the measurement weights for each measured variable to be equal for the three education groups. The goodness-of-fit indices for the constrained model produced adequate goodness-of-fit statistics $\left(x^{2} / \mathrm{df}=1.719 ; \mathrm{CFI}=0.904 ; \mathrm{RMSEA}=0.038\right)$. The comparison of the unconstrained and constrained model shows that the constrained model has equally good indices, therefore supporting metric invariance (Steenkamp \& Baumgartner, 1998).

\subsection{Hypotheses testing - single group}

The construct defining online acculturation relates to Language and Friendship Orientation. Offline acculturation is represented by Enculturation and Acculturation. Reviewing the structural parameter estimates of the structural model (Table 3) shows that all paths are significant. The structural model accounts for $27 \%$ of the variance in respondents' Purchase Intentions. The analysis reveals a negative significant influence of Friendship Orientation and Enculturation $(\beta=-0.096, \mathrm{p}=0.03)$ and a positive significant influence of Friendship Orientation and Acculturation $(\beta=0.40, p=0.00)$. Therefore, both $\mathrm{H} 1 \mathrm{a}$ and $\mathrm{H} 1 \mathrm{~b}$ are accepted.

Language Use has a negative significant influence on Enculturation $(\beta=-0.46, p=0.00)$ and a positive significant influence on Acculturation $(\beta=0.20, p=0.00)$. These findings support $\mathrm{H} 2 \mathrm{a}$ and $\mathrm{H} 2 \mathrm{~b}$.

Enculturation has a positive and significant influence on Purchase Intentions $(\beta=0.42$, $p=0.00)$ and the path between Acculturation and Purchase Intentions is positive and significant $(\beta=0.36, p=0.00)$. Findings provide support for $\mathrm{H} 3 \mathrm{a}$ and $\mathrm{H} 3 \mathrm{~b}$.

[Insert Figure 2 here]

[Insert Table 3 here] 


\subsection{Moderating role of education level}

The aim of this analysis is to compare and contrast hypotheses 1 to 3 across the three education groups to determine the moderating effects of education level on each of the causal links in our conceptual framework as shown in Figure 1. In terms of the link between Friendship Orientation and Enculturation (Hla), reviewing the structural parameter estimates (Table 4) show that the link becomes non-significant for each of the three groups conforming the moderating role of education level across the three groups. In terms of the link between Friendship Orientation on Acculturation $(H 1 b)$, the analysis shows that the relationship is significant but becomes weakest for Group $1(\beta=0.273, p=0.05)$, slightly weaker for Group 2 ( $\beta=0.39, p=0.00)$ but stronger for Group $3(\beta=0.43, p=0.00)$.

When it comes to the impact of Language Use on Enculturation (H2a), the analysis shows that the relationship remains negative but becomes stronger for Group $1(\beta=-0.50$, $p=0.00)$ and $2(\beta=-0.50, p=0.00)$ but weaker for Group $3(\beta=-0.38, p=0.00)$. Similarly, the analysis shows that the impact of Language Use on Acculturation (H2b) becomes stronger for Group $1(\beta=0.38, p=0.00)$ and non-significant for Group $2(\beta=0.15$, n.s. $)$ and $3(\beta=0.08$, n.s. $)$. In terms the impact of Enculturation on Purchase Intentions (H3a), the analysis shows that the relationship remains significant and is more or less same for Group $1(\beta=0.43, p=0.00)$, stronger for Group $2(\beta=0.46, p=0.00)$ and weaker for Group $3(\beta=0.39, p=0.00)$. Finally, in terms of the relationship between Acculturation and Purchase Intentions, the analysis shows that the relationship is significant but becomes stronger for Group $1(\beta=0.56, p=0.00)$ and Group $2(\beta=0.47, p=0.00)$ and much weaker for Group $3(\beta=0.25, p=0.00)$. Taken together, there is a strong evidence that education level moderates the intensity of various relationships conceptualized in our conceptual model (Figure 1) providing support for H4.

[Insert Figure 3 here]

[Insert Table 4 here] 


\section{Discussion}

This study extends existing research investigating online acculturation for both language use and friendship orientation in the use of social media. In consumer terms, the finding suggests that the individuals have become more acculturated (Peñaloza, 1994; Kara \& Kara, 1996), which is further expanded within online networks (Valenzuela et al., 2009). Friends on the same social networking website have a considerable influence on consumers (Hsu et al., 2011), consequently are more predisposed to bond, hold and share with social networks online (Brown et al., 2007). The results of this study show, that online acculturation occurs through online social networks. The study covers online acculturation through friendship orientation and language use as key drivers of acculturation preferences. The present research contributes to associate online with offline acculturation phenomena and consumers' decision making i.e. purchase intentions.

\subsection{Single group findings}

A key finding is that mainstream culture friendship orientation and language use positively impact acculturation. Moreover, and in line with previous research, this study finds that friendship orientation and language use negatively influence enculturation (Laroche et al., 2009; Kizgin et al., 2018b; Korzenny \& Korzenny, 2005; Yagmur, 2014). The negative effect on acculturation may be attributed to the process of consumers' learning and socialization (Peñaloza, 1994). A high degree of maintenance of the heritage culture, which entails interactions with friends and the media suggest that enculturated consumers are influenced by their online friends with preference of heritage culture orientation.

The findings of this study suggest that ethnic minority consumers rely on and are influenced by their online social networks. Research has indicated that similarity among media users foster social network relationships (Guéguen et al., 2011). This could explain the relationship between online (friendship and language use) and offline acculturation, whereas 
the personal-social information is defined by the computer-mediated bond individuals have. This might be related to the fact that the cultural, linguistic and psychological changes appear when undergoing acculturation (e.g. Kwak \& Berry, 2001). Research in psychology has argued that behavioral tendencies such as friendship orientation and language use, constitute the functional and social aspects of life like school or workplace (Arends-Tóth \& van de Vijver, 2006).

The study also finds that both enculturation and acculturation positively impact purchase intentions and are in line with prior research which argues that cultural orientations influence consumers' purchase intentions (Wang, Yu, \& Wei, 2012).

\subsection{Moderating role of education level}

The findings largely confirm the moderating role of education level and contribute to literature that argues for considering education as important predictor of consumer behavior (Berry et al., 2011; Ogden et al., 2004). The study further contributes to the scholarly work that argues that acculturation preferences and purchase preferences are impacted by linguistic fluency (Kwak \& Berry, 2001).

Education level seems to moderate the relationship between friendship orientation and enculturation across three groups to the extent that the relationship becomes non-significant. This is an unexpected finding and requires further research to fully investigate the reasons how and in what sense education plays such a role at least for those who are highly educated (Group $3)$.

The research also finds that education moderates the extent to which friendship orientation impacts acculturation such that the impact is strongest for highly educated individuals (Group 3) compared to those who are less educated (groups 1 and 2). Findings suggest highly educated individuals who seek and maintain relationships with mainstream individuals in an online context are more inclined to acculturate into mainstream culture in 
offline context than those with lower levels of education. This is a significant new insight and is in line with consumer acculturation research in offline context (Berry et al., 2011; Peñaloza, 1994) that has long argued that one's education level matters in determining the extent to which one acculturates into mainstream society and culture.

The study finds that education moderates the negative association between language use and enculturation such that the association becomes stronger for groups 1 and 2 but weaker for Group 3. This suggests that as the education level goes down, one's preference to use mainstream language on social media networking sites more strongly predicts their desire to maintain cultural maintenance in offline contexts. This shows that the more an individual uses mainstream language on social media platforms, the more likely it is that the person will avoid cultural maintenance and this is more so if the person is less educated. Findings imply that the more an individual assimilates via using mainstream language online, the more it has a negative effect on the maintenance of heritage culture. This is in line with offline consumer acculturation research (Ueltschy \& Krampf, 1997; Yagmur \& Van de Vijver, 2012) where language is taken as an approximate measure for the extent to which one can avoid cultural maintenance.

Moreover, the study finds that education moderates the impact of language use on acculturation such that the impact become stronger for least educated (Group 1) and nonsignificant for groups 2 and 3. Findings imply that the link only works for those who are least educated. In other words, if someone prefers to use mainstream language on social media, the person is likely to acculturate but only if the person is less educated. Less educated individuals appear to be more sensitive to adopt the mainstream culture where this is influenced by mainstream language use online. This unexpected result suggests that language policies in a society have an influence on adaptation i.e. acculturation as language is regarded as a social integration process (Yagmur \& van de Vijver, 2012). This result may also be attributed to assimilation ideology to embrace mainstream language. For example, Schecter and Bayley 
(1997) identify that parents are encouraged "to speak English whenever possible in the home in order not to 'create a conflict' that causes the child to experience problems in school" (p.518).

Furthermore, the study finds that education moderates the association between enculturation on purchase intentions such that the association becomes stronger for Group 2 and weaker for Group 3. Findings imply that offline preference for maintenance of heritage culture impacts purchase intentions more strongly for medium level educated people and less strongly for highly educated people. This is perhaps because medium level educated individuals are more likely to adhere and listen to the advice provided online in terms of making a specific purchase than those who are highly educated. This is in line consumer expertise and knowledge literature (Alba \& Hutchinson, 1987, 2000; Johnson \& Russo, 1984), which argues that knowledgeable and expert consumers are quite confident in their ability to make choices and, therefore, are more likely to ignore the opinion of others when making a purchase. Moreover and as per Laroche, Mourali and Pons (2005), higher educated individuals are less susceptible to interpersonal influence. Prior offline consumer acculturation research (e.g., Jamal, 2003) also reports that, generally speaking, those who prefer to maintain heritage culture are those who have collectivist orientations. It could be that within our sample, there are individuals who are collectivist in orientation and are highly educated avoiding the opinion of others when it comes to purchase intentions. Further research is, however, needed to fully explore the dynamics involved in understanding ethnic minority consumers' purchase intentions.

Finally, the study finds that education moderates the link between acculturation and purchase intentions such that the link becomes stronger for groups 1 and 2 and weaker for Group 3. Findings imply that the more an individual becomes educated, the less the effect of mainstream culture on their purchase intentions. Alternatively, as the education level goes down, the greater the effect of mainstream cultural preference on purchase intentions based on 
recommendations made online. It could be that a less educated ethnic minority consumer has the opportunity of living next door to a very good and friendly mainstream family. The person may have the opportunity to work with mainstream colleagues at work. During this interaction, the consumer may learn more about the mainstream culture and hence is more willing to accept recommendations when it comes to purchase intentions based on recommendations made online. In contrast and as argued earlier, more educated individuals are expected to have higher levels of knowledge. Such consumers are less likely to rely on the opinion of others when making purchases. This is in line with social psychological literature that argues that highly educated individuals have more confidence in their own abilities and do not necessarily need approval of others when making purchase decisions (Phalet \& Schönpflug, 2001).

\subsection{Theoretical contributions}

This study focuses on acculturation because it is an important theoretical as well as practical issue for ethnic marketing (Jamal et al., 2015). Scholarly work has long shown a keen interest in understanding the dynamics of consumption choices made by ethnic minority consumers pointing to language use and social interactions in offline context as key drivers of acculturation and consumption choices (Askegaard et al., 2005; Jamal, 2003; Kizgin et al., 2018a; Peñaloza, 1994). The current study contributes, in theoretical terms, firstly by reporting the significant effects of language use and friendship orientation in social media context on enculturation and acculturation in offline context. Further scholarly studies can further investigate the social and psychological underpinnings behind language use and friendship orientation among ethnic minorities in online contexts. Secondly, the study provides better insights into the cultural dynamics involved in understanding minority consumers' intentions to purchase based on recommendations made by others in social media context. It is clear from our study that an ethnic minority consumer's cultural orientation (acculturation and enculturation) can inform their tendencies to seek and act upon purchase-related opinions of 
others in a social media context. Future studies can investigate the nature, type and intensity of purchase related recommendations made online and the extent to which such recommendations feed into consumption choices made by ethnic minority consumers.

Furthermore, ethnic minority consumers segments exhibit different levels of education, and as such may not always exhibit same levels of acculturation in online and offline contexts. In line with consumer research that shows differences in consumer behavior as per levels of consumer expertise and knowledge structures (Alba \& Hutchinson, 1987, 2000; Johnson \& Russo, 1984), this study makes an important theoretical contribution to ethnic marketing (Jamal et al., 2015) and consumer acculturation research (Askegaard et al., 2005; Jamal, 2003; Kizgin et al., 2018a; Peñaloza, 1994) by reporting the moderating effects of education level on the links between friendship orientation and enculturation, friendship orientation and acculturation, language use and enculturation, enculturation and purchase intentions and acculturation and purchase intentions. Our findings point to the direction that an educationspecific analysis of ethnic minority consumers' acculturation in online and offline contexts provides more diagnostic value for understanding the cultural underpinnings of consumption choices. An aggregate theoretical analysis of ethnic minority consumers' acculturation and consumption choices ignoring education differences may lack depth and rigor and future research should investigate the moderating role of other demographic variables such as income, social and marital status and gender. While prior research has pointed to the important role of education level in impacting the extent to which one acculturates or not in an offline context, this research has contributed by investigating the contribution of various levels of education in enhancing or reducing online and offline acculturation phenomena and purchase intentions.

\subsection{Managerial implications}

Ethnic minority groups make substantial contributions to society, politics and economics (Jamal et al., 2019). Ethnic minorities embrace virtual media and seek to engage, 
develop and nurture their relationships trough online communication, which in turn reconciles with their offline acculturation preferences and are likely to use the social networks as a resource. The role of online acculturation as an agent in influencing offline acculturation is inherently related to consumption choices. As such, ethnic minority consumers acquire the "skills and knowledge relevant to engaging in consumer behavior" in a foreign cultural context (Peñaloza 1989, p.110) influenced by education, friends, media as a results of consumer learning processes (Askegaard et al., 2005), result in home or host consumer behavior.

In practical terms, it can be concluded that both enculturation and acculturation levels in offline contexts can be improved substantially by focusing on language use and friendship orientation in social media context. This is significant given social media marketers can use and reach out to customer segments (Kapoor et al., 2018). Digital marketing business should harness the use of social media to promote the continued engagement of the ethnic minority communities through online acculturation. The findings provide an understanding of language use and friendship orientations. This is relevant information to attract ethnic minority consumers to business networks. A useful insight is to segment social network followers by language use for communications, advertisements and further development of social media strategies (Kizgin et al., 2020). The success of social media strategies depends largely on appropriate targeting, while businesses pursue relationships with users with a compatible background (Kapoor et al., 2018). Kapoor et al. (2018) performed a comprehensive review of the studies and found a widespread role of community structure and structural designs toward using social media for marketing related aspects. It was argued that the success of marketing through social media channels is contingent on recognizing customer segments and targeting them based on their demographic patterns and related interests.

The negative and significant influence of language use on the social media platforms onto offline enculturation indicates that public and private firms should take a good account of 
language preferences for the various groups of consumers as per their level of education and whether they want to use their own local language or the mainstream language while interacting with others on social media platforms. Given that all respondents preferring to use the mainstream language in the online context show non-preference for offline enculturation, business in The Netherlands should target such consumers in the mainstream language (Kizgin et al., 2018b).

The significant impact of only a small fraction of respondents using the mainstream language to adopt the host culture indicates that local businesses in the Netherlands should use the message strategies that are largely aligned to the ethnic minority consumers' culture. Likewise, significant influence of online friendship orientation for the majority of highly educated ethnic minority consumers on offline acculturation and minority of respondents on offline enculturation indicates that businesses in the Netherlands should follow the similar strategy as they use to attract local consumers. Moreover, the Netherlands is composed of different cultures with Turkish-Dutch being the largest emerging non-Western ethnic community (Vista, 2007), and public and private businesses should seriously consider their enculturation and acculturation preferences to understand their purchase intentions.

\subsection{Limitations and future research directions}

This study contains some minor limitations. The first limitation concerns the lower sample size in Education Group 1. This might be explained by digital illiteracy. The study did not include the multidimensional tie strength construct. Tie strength may range from close friends to acquaintances, the types of resources and frequency of relationship exchanges as well as the intimacy (Marsden \& Campbell, 1984). Future research could include this construct to contribute further to the topic of online acculturation.

Given that online advertising is related to cultural identification, future research should consider the influence of web advertising on ethnic minority consumers' consumption patterns. 
Large ethnic minority subcultures exist across the Western world (Laroche \& Jamal, 2015). Access to social media connects different likeminded people as well as providing support to maintain and establish social relationships (Tang et al., 2015).

Previous research showed that consumers' social media use relates to brand quality relationships (Hudson et al., 2016). Future research could examine how social media use influences brand trust and online shopping. Given the visibility and economic power of ethnic consumer groups, this points to a particular area where greater understanding can be achieved.

\section{Conclusion}

This study finds that friendship orientation for low education level individuals has a positive influence on enculturation whereas it has a non-significant influence on acculturation. However, friendship orientation for relatively higher education level individuals has a nonsignificant influence on enculturation whereas it exerts a significant influence on acculturation. Language use for individuals of every education level is understandably found to be significant on enculturation whereas only individuals with lower education level were found to have significant influence on acculturation. This clearly indicates that use of language does not matter much for ethnic minority consumers with relatively higher education level to adopt and mixed up with the individuals with host culture.

A significant contribution of this research is to have the access of large sample of ethnic minority consumers with host country's groups and understanding their purchase intentions based on different education levels. Understanding the impact of ethnic minority consumers' friendship orientations and language use on their acculturation preferences on social media platforms is another contribution of this research.

\section{References}

Acquisti, A., \& Gross, R. (2006). Imagined communities: Awareness, information sharing, and privacy on the Facebook. In P. Golle \& G. Danezis (Eds.), Proceedings of 6th Workshop on Privacy Enhancing Technologies (pp. 36-58). Cambridge, UK: Robinson College. 
Alalwan, A. A., Rana, N. P., Dwivedi, Y. K., \& Algharabat, R. (2017). Social media in marketing: A review and analysis of the existing literature. Telematics and Informatics, 34(7), 1177-1190.

Alba, J.W. and Hutchinson, J.W. (1987). Dimensions of consumer expertise. Journal of Consumer Research, 13(4), 411-54.

Alba, J.W. and Hutchinson, J.W. (2000). Knowledge calibration: what consumers know and what they think they know. Journal of Consumer Research, 27(2), 123-56.

Arends-Tóth, J. V., \& van de Vijver, F. J. R. (2006). Assessment of psychological acculturation: Choices in designing an instrument. The Cambridge handbook of acculturation psychology. D. L. Sam, \& J. W. Berry (Eds.) (pp. 142-160). Cambridge: Cambridge University Press.

Arends-Tóth, J.V., \& van de Vijver, F.J.R. (2007). Acculturation attitudes: A comparison of measurement methods. Journal of Applied Social Psychology, 37(7), 1462-1488.

Arends-Tóth, J.V., \& van de Vijver, F.J.R. (2008). Family relationships among immigrants and majority members in the Netherlands: The role of acculturation. Applied Psychology: An International Review, 57(3), 466-487.

Askegaard, S., Arnould, E. J., \& Kjeldgaard, D. (2005). Postassimilationist ethnic consumer research: Qualifications and extensions. Journal of Consumer Research, 32(1), 160-170.

Bercerra, E.P., \& Korgaonkar, P.K. (2010). The influence of ethnic identification in digital advertising: How Hispanic Americans' response to pop-up, e-mail, and banner advertising affects online purchase intentions, Journal of Advertising Research, 50(3), 279-291.

Berry, J.W., Poortinga, Y.H., Breugelmans, S.M., Chasiotis, A., \& Sam, D.L. (2011). CrossCultural Psychology. Research and Applications. Cambridge: University Press.

Brown, J., Broderick, A. J., \& Lee, N. (2007). Word of Mouth Communication within Online Communities: Conceptualizing the Online Social Network. Journal of Interactive Marketing, $2-20$.

Burton, D. (2002). Incorporating ethnicity into marketing intelligence and planning. Market Intelligence and Planning, 20(7), 442-451.

Byrne, B. M. (2009). Structural equation modeling with AMOS: Basic concepts, applications, and programming (2nd ed.). New York: Routledge/Taylor \& Francis.

Byrne, B. M., \& van de Vijver, F. J. R. (2010). Testing for measurement and structural equivalence in large-scale cross-cultural studies: Addressing the issue of nonequivalence. International Journal of Testing, 10(2), 107-132.

Chang, H.H., \& Chuang, S-S. (2011). Social capital and individual motivations on knowledge sharing: Participant involvement as a moderator. Journal Information \& Management 48(1), 9-18. 
Cheung, G. W., \& Rensvold, R. B. (2002). Evaluating goodness-of-fit indexes for testing measurement invariance. Structural Equation Modeling, 9(2), 233-255.

Coyle, J.R., \& Thorson, E. (2001). The effects of progressive levels of interactivity and vividness in Web marketing sites. Journal of Advertising 30(3), 65-77.

Dey, B. L., Yen, D., \& Samuel, L. (2020). Digital consumer culture and digital acculturation. International Journal of Information Management, 51, 102057.

Deshpande, R., Hoyer, W.D., \& Donthu, N. (1986). The intensity of ethnic affiliation: A study of the sociology of Hispanic consumption. Journal of Consumer Research, 13(2), 214-220.

Dwivedi, Y. K., Kapoor, K. K., \& Chen, H. (2015). Social media marketing and advertising. The Marketing Review, 15(3), 289-309.

Ellison, N.B., Steinfield, C., \& Lampe, C. (2007). The benefits of Facebook "friends": Exploring the relationship between college students' use of online social networks and social capital. Journal of Computer-Mediated Communication, 12(4), 1143-1168.

Ellison, N.B., \& Boyd, D. (2013). Sociality through social network sites. In Dutton, W.H. (Ed.), The Oxford Handbook of Internet Studies (151-172). Oxford: Oxford University Press.

Eurostat (2019). Are you using social networks? Eurostat: Your Key to European Statistics. Accessed from https://ec.europa.eu/eurostat/web/products-eurostat-news/-/EDN-20190629-1 on April 4, 2020.

Fornell, C., \& Larcker, D. F. (1981). Evaluating structural equation models with unobservable variables and measurement error. Journal of Marketing Research, 18(1), 39-50.

Foroudi, P., Marvi, R. \& Kizgin, H. (2020). The OTHERS: The Role of Individual Personality, Cultural Acculturation, and Perceived Value on towards Firm's Social Media and Acculturation Orientation. International Journal of Information Management, 102075.

Guéguen, N., Martin, A., \& Meineri, S. (2011) Similarity and social interaction: when similarity fosters implicit behavior toward a stranger. Journal of Social Psychology, 151, 671673.

Gupta, N. (2012). The impact of globalization on consumer acculturation. Asia Pacific Journal of Marketing and Logistics, 24(1), 41-58.

Hair, J.F., Black, W.C., Babin, B.J., \& Anderson, R.E. (2010). Multivariate Data Analysis (7th ed.) Upper Saddle River, NJ: Prentice-Hall.

Hassler, T., Gonzalez, R., Lay, S., Lickel, B., Zagefka, H., Tropp, L. R., ... \& Bernardino, M. (2019). With a little help from our friends: The impact of cross-group friendship on acculturation preferences. European Journal of Social Psychology, 49(2), 366-384.

Hilte, L., Vanderkerckhove, R., \& Daelemans, W. (2016). Expressiveness in Flemish online teenage talk: A corpus-based analysis of social and medium-related linguistic variation. In 
Proceedings of the 4th Conference on CMC and Social Media Corpora for the Humanities, D. Fiser \& M. Beisswenger (eds.) (30-33), Ljubljana, Slovenia.

Hu, L., \& Bentler, P. M. (1999). Cutoff criteria for fit indexes in covariance structure analysis: Conventional criteria versus new alternatives. Structural Equation Modeling, 6, 1-55.

Hsu, C.-W., Wang, C.-C., \& Tai, Y.-T. (2011). The closer the relationship, the more the interaction on Facebook? Investigating the case of Taiwan users. Cyberpsychology, Behavior, and Social Networking, 14(7-8), 473-476.

Hudson, S., Huang, L., Roth, M. S., \& Madden, T. J. (2016). The influence of social media interactions on consumer-brand relationships: A three-country study of brand perceptions and marketing behaviors. International Journal of Research in Marketing, 33(1), 27-41.

Hui, M., Joy, A., Kim, C., \& Laroche, M. (1992). Acculturation as a determinant of consumer behavior: Conceptual and methodological issues, American Marketing Association, 3, 466473.

Jackson, L.A., \& Wang, J.L. (2013). Cultural differences in social networking site use: A comparative study of Chine and the United States. Computers in Human Behavior, 29(3), 910921.

Jafari, A., \& Visconti, L. (2015). New directions in researching ethnicity in marketing and consumer behaviour: A wellbeing agenda, Marketing Theory, 15(2), 265-270.

Jamal, A., Peñaloza, L., \& Laroche, M. (2015). Introduction to Ethnic Marketing, The Routledge Companion to Ethnic Marketing. London, Routledge.

Johnson, E.J. and Russo, J.E. (1984). Product familiarity and learning new information. Journal of Consumer Research, 11(1), 542-50.

Khairullah, D. Z., \& Khairullah, Z. Y. (1999). Relationships between acculturation, attitude toward the advertisement, and purchase intention of Asian-Indian immigrants. International Journal of Commerce and Management, 46-46.

Kaplan, A.M., \& Haenlein, M. (2010). Users of the world, unite! The challenges and opportunities of social media. Business Horizons, 53(1), 59-68.

Kapoor, K. K., Tamilmani, K., Rana, N. P., Patil, P., Dwivedi, Y. K., \& Nerur, S. (2018). Advances in social media research: Past, present and future. Information Systems Frontiers, 20(3), 531-558.

Kara A, \& Kara N.R. (1996). Ethnicity and consumer choice: A study of Hispanic decision processes across different acculturation levels. Journal of Applied Business Research,12(2), $22-35$.

Keefe, S. E. \& Padilla, A. M. (1987). Chicano ethnicity. Albuquerque, NM: University of New Mexico Press. 
Khairullah, D.Z., \& Khairullah, Z.Y. (1999). Behavioural acculturation and demographic characteristics of Asian-Indian immigrants in the United States of America. International Journal of Sociology and Social Policy, 19(1), 57-80.

Kim, Y., Sohn, D., \& Choi, S. M. (2011). Cultural difference in motivations for using social network sites: A comparative study of American and Korean college students. Computers in Human Behavior, 27(1), 365-372.

Kizgin, H., Jamal, A. \& Richard, M-O (2018a). Consumption of products from heritage and host cultures: the role of acculturation attitudes and behaviors. Journal of Business Research, $82,320-329$.

Kizgin, H., Jamal, A., Dey, B.L. and Rana, N. P. (2018b). The Impact of Social Media on Consumers' Acculturation and Purchase Intentions. Information Systems Frontiers, 20(3), $503-$ 514.

Kizgin, H., Dey, B., Dwivedi, Y.D., ......Rana, N.P. et al. (2020). The impact of Social Media on Consumer Acculturation: Current Challenges, Opportunities, and Agenda for Research and Practice. International Journal of Information Management, 51, 102026, DoI: 10.1016/j.ijinfomgt.2019.10.011

Kline, R.B. (2011). Principles and Practice of Structural Equation Modeling, 3rd Edition. New York, NY: The Guilford Press.

Korzenny, F., \& Korzenny, B.A. (2005). Hispanic Marketing: A Cultural Perspective. Burlington: Elsevier Butterworth-Heinmann.

Kwak, K., \& Berry, J. W. (2001). Generational differences in acculturation among Asian families in Canada: A comparison of Vietnamese, Korean, and East-Indian groups. International journal of psychology, 36(3), 152-162.

Laroche, M., Chung, K.K., \& Clarke, M. (1997). The effects of ethnicity factors on consumer deal interests: An empirical study of French- and English-Canadians. Journal of Marketing Theory \& Practice, 5(1), 100-112.

Laroche, M., Mourali, M. \& Pons, F. (2005). Individualistic orientation and consumer susceptibility to interpersonal influence. Journal of Services Marketing, 19(3), 164-173.

Laroche, M., Pons, F., \& Richard, M.O. (2009). The role of language in ethnic identity measurement: A multitrait-multimethod approach to construct validation. Journal of Social Psychology, 149(4), 513-539.

Laroche, M., \& Jamal, A. (2015). Models of culture change. In The Routledge Companion to Ethnic Marketing. (17-35): Routledge.

Laumann, E. O. (1966). Prestige and association in an urban community: An analysis of an urban stratification system. Bobbs-Merrill Company. 
Leung, K., Bhagat, R.S., Buchan, N.R., Erez, M. \& Gibson, C.B. (2005). Culture and international business: recent advances and their implications for future research. Journal of International Business Studies, 36(4), 357-78.

Li, C.L., \& Tsai, W.H. (2015). Social media usage and acculturation: A test with Hispanics in the U.S. Computers in Human Behavior, 45, 204-212.

Lin, N., Cook, K., \& Burt, R. (2001). Social capital: Theory and research. New York: Aldine de Gruyter.

Lindridge, A., Henderson, G.R., \& Ekpo, A.E. (2015). (Virtual) ethnicity, the Internet, and well-being. Marketing Theory, 15(2), 279-285.

Luedicke, M.K. (2011). Consumer acculturation theory: (crossing) conceptual boundaries. Consumption Markets \& Culture, 14(3), 223-244.

Lueg, J.E \& Finney, RZ (2007). Interpersonal Communication in the Consumer Socialisation process: Scale Development and Validation, Journal of Marketing Theory \& Practice, vol.15, no.1, viewed 20/012/12, EBSCO Host Research Database. Business Source Premier.

Makarova, E., \& Birman, D. (2016). Minority Students' Psychological Adjustment in the School Context: An Integrative Review of Qualitative Research on Acculturation. Intercultural Education 27(1), 1-21.

Maldonado, R., \& Tansuhaj, P. (2002). Segmenting a local Latino market using Berry's acculturation taxonomy. In Advances in Consumer Research, 29. S.M. Broniarczyk, K. Nakamoto, \& G.A. Valdosta (eds.), Association for Consumer Research, 414-420.

Marsden, P. V., \& Campbell, K. E. (1984). Measuring tie strength. Social Forces, 63(2), 482501.

Mendoza, R.H. (1989). An empirical scale to measure type and degree of acculturation in Mexican American adolescents and adults. Journal of Cross-Cultural Psychology, 20(4), 372385 .

Ogden, D. T., Ogden, J. R., \& Schau, H. J. (2004). Exploring the impact of culture and acculturation on consumer purchase decisions: Toward a microcultural perspective. Academy of Marketing Science Review, 3(1), 1-22.

Padilla, A. M. (1980). The role of cultural awareness and ethnic loyalty in acculturation. Acculturation: Theory, Models and Some New Findings, 47-84.

Park, H., \& Cho, H. (2012). Social network online communities: information sources for apparel shopping. Journal of Consumer Marketing, 29(6), 400-411.

Phalet, K., \& Schönpflug, U. (2001). Intergenerational transmission of collectivism and achievement values in two acculturation contexts: The case of Turkish families in Germany and Turkish and Moroccan families in the Netherlands. Journal of cross-cultural psychology, 32(2), 186-201. 
Peñaloza, L. (1989). Immigrant Consumer Acculturation. Advances in Consumer Research, $16,110-118$.

Peñaloza, L. (1994). Atravesando Fronteras/border crossings: A critical ethnographic exploration of the consumer acculturation of Mexican immigrants. Journal of Consumer Research, 21(1), 32-54.

Peñaloza, L. and Gilly, M. C. (1999). Marketer acculturation: the changer and the changed. Journal of Marketing, 63, 84-104.

Quarasse, O., \& van de Vijver, F. J. R. (2004). Structure and function of the perceived acculturation context of young Moroccans in the Netherlands. International Journal of Psychology, 39(3), 90-204.

Schwartz, S.J., Unger, J.B., Zamboanga, B.L., \& Szapocznik, J. (2010). Rethinking the concept of acculturation: Implications for theory and research. American Psychologist, 65, 237-251.

Schecter, S. R., \& Bayley, R. (1997). Language socialization practices and cultural identity: Case studies of Mexican-descent families in California and Texas. Tesol Quarterly, 31(3), 513541.

Shen, G, Chiou, J, Hsiao, C., Wang, C. \& Li, H. (2016). Effective marketing communication via social networking sites: The moderating role of the social tie. Journal of Business Research, 69, 2265-2270.

Tang, J., Zhang, P., \& Wu, P. (2015). Categorizing consumer behavioral responses and artifact design features: The case of online advertising. Information Systems Frontiers, 17(3), 513532.

Ueltschy, L. C. \& Krampf, R. F. (1997). The Influence of Acculturation on Advertising Effectiveness to the Hispanic Market. Journal of Applied Business Research, 13(2), 87-101.

Valenzuela, S., Park, N., \& Kee, K.F. (2009). Is there social capital in a social network site?: Facebook use and college students' life satisfaction, trust, and participation. Journal of Computer-mediated Communication, 14, 875-901.

Van De Vijver, F. J., \& Phalet, K. (2004). Assessment in multicultural groups: The role of acculturation. Applied Psychology, 53(2), 215-236.

Vista, E. (2007). From ethnic minorities to ethnic majority policy: multiculturalism and the shift to assimilationism in the Netherlands. Ethnic and Racial Studies, 30(5), 713-740.

Wang, X., Yu, C., \& Wei, Y. (2012). Social media peer communication and impact on purchase intentions: A consumer socialization framework. Journal of Interactive Marketing, 26, 198-208.

Xu, J., Shim, S., Lotz, S., \& Almeida, D. (2004). Ethnic identity, socialization factors, and culture-specific consumption behavior. Psychology \& Marketing, 2(21), 93-112. 
Yagmur, K. (2014). Intergenerational differences in acculturation orientations of Turkish speakers in Australia. Journal of Social Sciences in the Turkish World, 70, 237-258.

Yagmur, K., \& van de Vijver, F.J.R. (2012). Acculturation and language orientations of Turkish immigrants in Australia, France, Germany, and the Netherlands. Journal of CrossCultural Psychology, 43(7), 1110-1130.

Yaprak, A. (2008). Culture study in international marketing: a critical review and suggestions for future research. International Marketing Review, 25(2), 215-229.

Yu, Q., Foroudi, P., \& Gupta, S. (2019). Far apart yet close by: Social media and acculturation among international students in the UK. Technological Forecasting and Social Change, 145, 493-502.

Figure 1 Proposed Conceptual Model

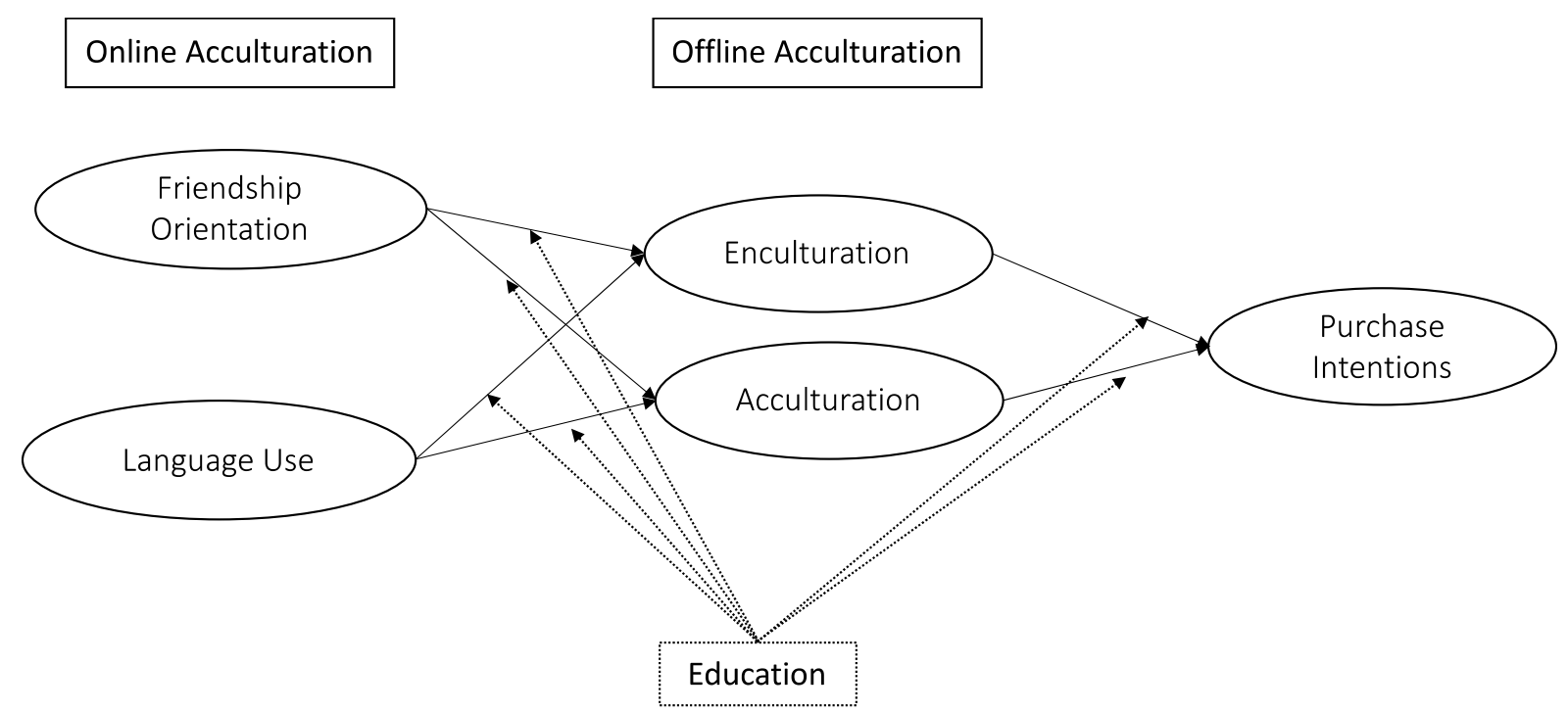




\section{Enculturation}

$(\alpha=0.932$, Composite reliability $=0.931, \mathrm{AVE}=0.600)$

I spend most of my social time with Turkish people.

$\begin{array}{llll}0.802 & 0.865 & 0.803 & 0.772 \\ 0.805 & 0.843 & 0.840 & 0.756 \\ 0.815 & 0.834 & 0.814 & 0.814 \\ 0.819 & 0.861 & 0.799 & 0.802 \\ 0.779 & 0.800 & 0.804 & 0.753 \\ 0.705 & 0.759 & 0.685 & 0.707 \\ 0.746 & 0.764 & 0.723 & 0.754 \\ 0.757 & 0.896 & 0.689 & 0.736 \\ 0.735 & 0.860 & 0.704 & 0.712\end{array}$

I very often ask for help/advice from Turkish students/colleagues.

I frequently eat with Turkish friends/colleagues.

My preference is to speak the Turkish language most of the time.

I very often speak in the Turkish language with my Turkish

friends.

I very often speak in the Turkish language with my parents and

family members.

I very often attend Turkish cultural performances (e.g., theatres

and concerts).

I very often watch Turkish movies.

I very often listen to Turkish music.

Acculturation

$(\alpha=0.911$, Composite reliability $=0.909, \mathrm{AVE}=0.529)$

I spend most of my social time with Dutch people.

I often ask for help/advice from Dutch students/colleagues.

0.785

0.786

0.794

0.773

I frequently eat with Dutch friends/colleagues.

0.835

0.815

0.849

0.823

My preference is to speak in the Dutch language most of the time.

0.755

0.643

0.830

0.720

I very often speak in the Dutch language with Turkish friends.

0.770

0.809

0.740

0.768

I very often speak in the Dutch language with my parents and

0.665

0.707

0.605

0.694

I very often attend Dutch cultural performances (theatres and concerts).

$\begin{array}{lll}0.642 & 0.643 \quad 0.610\end{array}$

0.660

0.656

0.690

0.658

0.629

I very often listen to Dutch music.

0.578

0.730

0.556

0.519

Friendship Orientation

$(\alpha=0.899$, Composite reliability $=0.890, \mathrm{AVE}=0.618)$

Most of my friends on social network sites are

0.722

0.693

0.683

0.748

I get together with other friends from social network sites

very often

0.796

0.766

0.838

0.764

It is important for me to connect with friends on social network sites

0.764

0.813

0.766

0.744

I prefer to hang out with friends rather than friends

from other ethnic groups on social network sites.

0.931

0.866

0.825

0.830

I see more commonalties between me and friends

rather than friends from other ethnic backgrounds on social

0.813

0.733

0.832

0.824

network sites

Language Use

$(\alpha=0.892$, Composite reliability $=0.893, \mathrm{AVE}=\mathbf{0 . 5 8 3})$

I like to read online news.

I like to participate in online content communities.

0.750

0.796

0.687

I like to read online collaborative projects.

0.828

0.854

0.838

0.823

I tend to post/read online blogs.

0.801

0.765

0.863

0.751

I like to be in virtual social worlds.

0.719

0.714

0.706

0.728

\section{Purchase Intentions}

$(\alpha=0.898$, Composite reliability $=0.899, \mathrm{AVE}=0.689)$

It is very likely that I will buy the product/service.

I will purchase the product/service next time I need the product/service. 
Table 2 Mean differences between consumers by education level

\begin{tabular}{llllllllrrr}
\hline & \multicolumn{2}{l}{$\begin{array}{l}\text { Education } \\
\text { Level 1 }\end{array}$} & \multicolumn{2}{l}{$\begin{array}{l}\text { Education } \\
\text { Level 2 }\end{array}$} & \multicolumn{2}{c}{$\begin{array}{l}\text { Education } \\
\text { Level 3 }\end{array}$} & $\begin{array}{l}\text { Effect } \\
\text { Size 1 }\end{array}$ & $\begin{array}{l}\text { Effect } \\
\text { Size 2 }\end{array}$ & $\begin{array}{l}\text { Effect } \\
\text { Size 3 }\end{array}$ \\
\cline { 2 - 11 } Construct & M & SD & M & SD & M & SD & & & \\
\hline Friendship Orientation & 2.38 & 0.76 & 2.32 & 0.78 & 2.46 & 0.79 & 0.08 & -0.10 & -0.18 \\
Language Use & 2.20 & 0.83 & 2.29 & 0.78 & 2.38 & 0.76 & -0.11 & -0.23 & -0.12 \\
Turkish Enculturation & 4.17 & 1.99 & 3.94 & 1.70 & 3.69 & 1.73 & 0.12 & 0.26 & 0.15 \\
Dutch Acculturation & 3.78 & 1.89 & 4.4 & 1.63 & 4.41 & 1.66 & -0.35 & -0.35 & -0.01 \\
Purchase Intentions & 3.79 & 1.63 & 4.03 & 1.53 & 3.77 & 1.64 & -0.15 & 0.01 & 0.16 \\
\hline
\end{tabular}

Effect size is defined as the difference of the Education Level mean score, divided by the standard deviation of the difference scores. Notes: ${ }^{a}$ represents the effect size between education level 1 and $2 .{ }^{b}$ represents the effect size between education level 1 and $3 .^{c}$ represents the effect size between education level 2 and 3.

Figure 2 Structural Model - single group

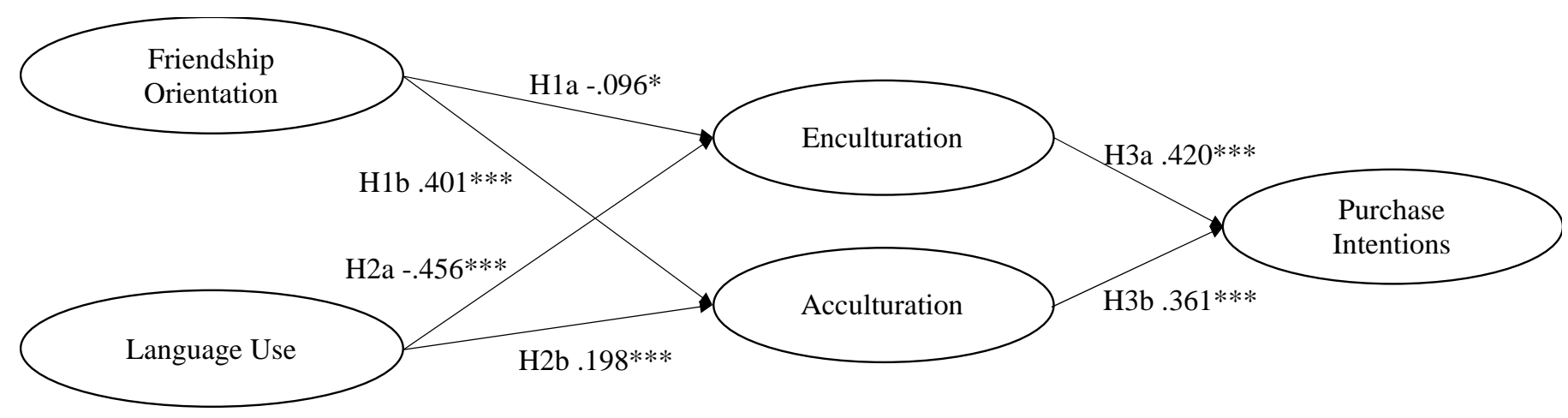

Table 3 Structural model estimates - single group

Estimates Std. Error C.R. $\quad p \quad$ St.

Estimates

Structural Model - single group

H1a Friendship Orientation $\rightarrow$ Enculturation

H1b Friendship Orientation $\rightarrow$ Acculturation

$-0.196$

0.091

$-2.149$

0.032

$-0.096$

$\mathrm{H} 2 \mathrm{a}$ Language Use $\rightarrow$ Enculturation

0.593

0.080

7.422

0.000

0.401

$\mathrm{H} 2 \mathrm{~b}$ Language Use $\rightarrow$ Acculturation

$-1.121$

0.124

$-9.041$

0.000

$-0.456$

H3a Enculturation $\rightarrow$ Purchase Intentions

0.351

0.084

4.174

0.000

0.198

$\mathrm{H} 3 \mathrm{~b}$ Acculturation $\rightarrow$ Purchase Intentions

0.427

0.048

8.985

0.000

0.420

0.508

0.071

$7.139 \quad 0.000$

0.361 
Figure 3 Structural Equation Modelling

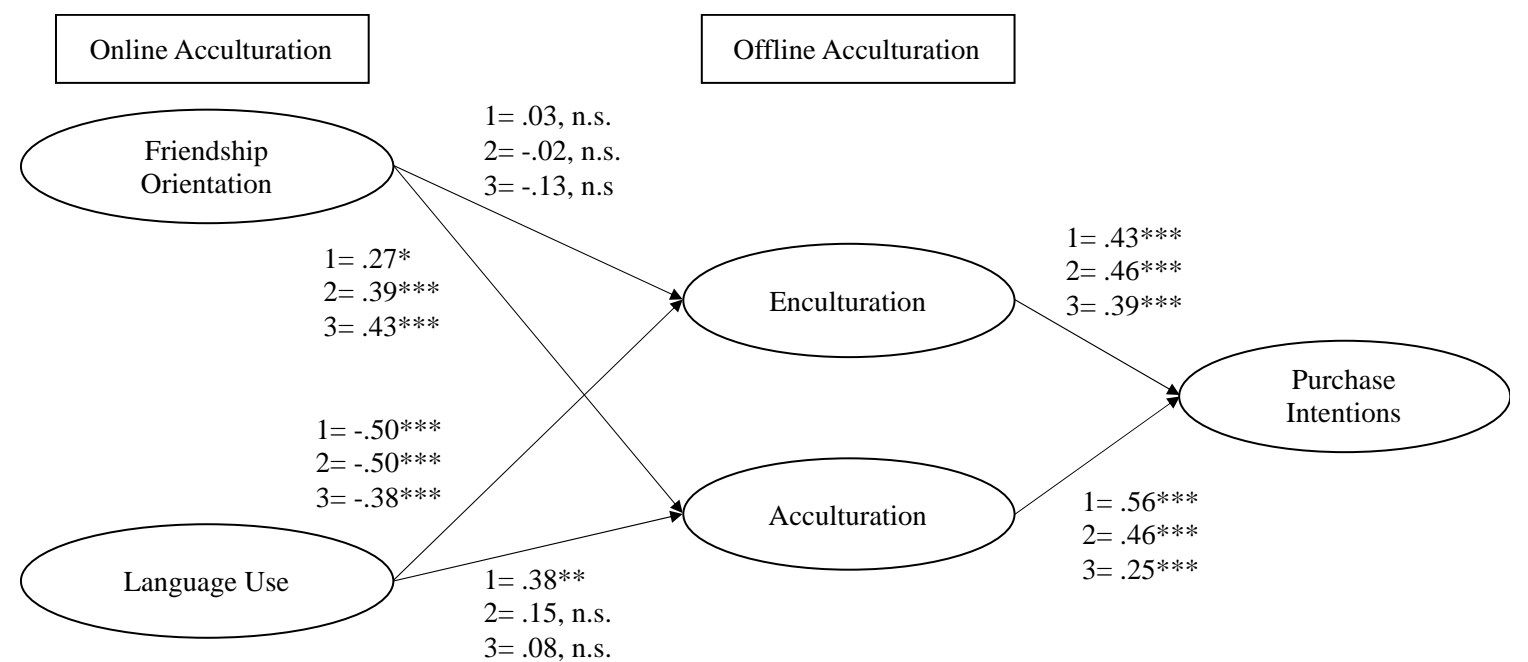

Note: Education Group 1=1, Education Group 2=2, Education Group 3=3

Table 4 Structural model estimates - multi-group

\begin{tabular}{lccccc}
\hline & Estimates & Std. Error & C.R. & $p$ & $\begin{array}{c}\text { St. } \\
\text { Estimates }\end{array}$ \\
\hline Structural Model $\rightarrow$ multi-group & & & & & \\
Education Group 1 & & & & & \\
H1a Friendship Orientation $\rightarrow$ Enculturation & 0.077 & 0.349 & 0.221 & 0.825 & 0.030 \\
H1b Friendship Orientation $\rightarrow$ Acculturation & 0.612 & 0.310 & 1.970 & 0.049 & 0.273 \\
H2a Language Use $\rightarrow$ Enculturation & -1.379 & 0.410 & -3.361 & 0.000 & -0.500 \\
H2b Language Use $\rightarrow$ Acculturation & 0.911 & 0.343 & 2.654 & 0.008 & 0.380 \\
H3a Enculturation $\rightarrow$ Purchase Intentions & 0.363 & 0.100 & 3.637 & 0.000 & 0.425 \\
H3b Acculturation $\rightarrow$ Purchase Intentions & 0.547 & 0.131 & 4.165 & 0.000 & 0.557 \\
Education Group 2 & & & & & \\
H1a Friendship Orientation $\rightarrow$ Enculturation & -0.046 & 0.163 & -0.284 & 0.776 & -0.022 \\
H1b Friendship Orientation $\rightarrow$ Acculturation & 0.529 & 0.125 & 4.239 & 0.000 & 0.393 \\
H2a Language Use $\rightarrow$ Enculturation & -1.262 & 0.224 & -5.634 & 0.000 & -0.500 \\
H2b Language Use $\rightarrow$ Acculturation & 0.251 & 0.133 & 1.889 & 0.059 & 0.153 \\
H3a Enculturation $\rightarrow$ Purchase Intentions & 0.448 & 0.073 & 6.177 & 0.000 & 0.459 \\
H3b Acculturation $\rightarrow$ Purchase Intentions & 0.670 & 0.128 & 5.240 & 0.000 & 0.446 \\
Education Group 3 & & & & & \\
H1a Friendship Orientation $\rightarrow$ Enculturation & -0.257 & 0.146 & -1.761 & 0.078 & -0.133 \\
H1b Friendship Orientation $\rightarrow$ Acculturation & 0.592 & 0.126 & 4.707 & 0.000 & 0.430 \\
H2a Language Use $\rightarrow$ Enculturation & -0.889 & 0.189 & -4.711 & 0.000 & -0.382 \\
H2b Language Use $\rightarrow$ Acculturation & 0.137 & 0.126 & 1.091 & 0.275 & 0.083 \\
H3a Enculturation $\rightarrow$ Purchase Intentions & 0.418 & 0.078 & 5.382 & 0.000 & 0.385 \\
H3b Acculturation $\rightarrow$ Purchase Intentions & 0.380 & 0.112 & 3.391 & 0.000 & 0.249 \\
\hline
\end{tabular}

